\title{
Adverse Selection Risk Early-Warning of Agricultural Insurance Towards Food Quality Safety — Illustrated by an example of vegetable sites in Shandong province
}

\author{
Dongling ZHANG \\ School of Economics, Qingdao University, Qingdao 266071, China \\ E-mail: zhangdongling99@126.com \\ Zehui YANG \\ China Certification \& Accreditation Institute, Beijing 100020, China
}

\begin{abstract}
From the perspective of the agricultural food quality safety, for the adverse selection because of the asymmetric information in agricultural insurance, an analysis approach based on multiclassification discrete choice model is proposed. On the basis of building an agricultural food safety risk evaluation index system, applying the linguistic information processing method, the panel valuation data is aggregated to obtain the integrated evaluation values. An ordered logistic model is put forward, and the calculation analysis steps are given. This research is illustrated by an example of export vegetable sites in Shandong province. The research indicates that the quality safety is the new component of agricultural risk, and the effective risk analysis can be on guard against the adverse selection in agricultural insurance practice. As well the linguistic information can be effectively aggregated with less lost by this method, the classes of agricultural food quality risk are ordinal, and approach will promote the extension and application in agricultural insurance to crop farming.
\end{abstract}

Keywords agricultural insurance; adverse selection; quality safety; agricultural risk; linguistic information; good agricultural practice

\section{Introduction}

Agricultural insurance is one of the three pillars of the modern agriculture development. As the WTO allows countries to support agriculture "green box policy", Agricultural insurance has strong welfare effect, credit support and policy effect to the development of agriculture and national economy ${ }^{[1]}$. Under the economic globalization, complicated and severe international economic situation, the development of agriculture and rural areas has become a powerful supporting of the steady. However, it also faces the impact of rising and complex global climate change, competition of international trade, environmental resource constraints and uncertainty risk fierce. In the current strategic period of promoting agriculture by applying scientific and technological advances, the development of agricultural insurance can not only scatter our natural risk of national agricultural production, implement the economic compensation before

Received October 16, 2014, accepted December 22, 2014

Supported by the Ministry of Educational Humanities and Social Sciences Foundation of China (10YJC630372) and the Project of Shandong Province Higher Educational Science and Technology Program (J14WE25) 
and after agricultural production, as well as stabilize farmers' income. On the other hand, the credit level of the agricultural management main body will be improved, and the stability of the rural financial system will be promoted. The effective agricultural insurance can improve agricultural production management level and international competitiveness, which is important part of solving the "three agricultural" problems.

However, in the practice of agricultural insurance, due to the particularity of agricultural risk, the adverse selection and moral hazard problems become a seriously barrier to the development of agricultural insurance. Meanwhile, because agriculture has not insurable risk, demand for agricultural insurance has the characteristics of complexity, and the supply of agricultural insurance faces the systemic risk, furthermore information asymmetry is serious. The former determines the high cost of compensation of agricultural insurance supply and the latter causes high cost of management of agricultural insurance supply. Ahsan et al. developed the theory and model of crop insurance market on the basis of the adverse selection of Rothschild insurance market ${ }^{[1]}$. They indicated that it was a large expense of information gathering and dissemination in the crop insurance market. At the same time, crop insurance was provided directly by the public sector, which leads to the incomplete information. Farmers could choose their own favorable conditions according to insurance contract, and the insurance agent would also cater to the needs of farmers in order to maximize respective interests. Therefore, agricultural insurance market that could spread risks effectively did not exist. According to the results of Quiggin, Coble et al., Miranda et al. ${ }^{[2-5]}$. They found that the cause of the failure in the agricultural insurance market mainly had four aspects: the perceived failure, insufficient effective demand, the systematic risk and asymmetric information. The first two factors would affect the demand for insurance and the latter two would limit the supply of insurance. Chambers, Hyde and Vercammen showed that because of the unobservability in which agricultural insurance's earnings were subject to the insured and opportunistic behavior, adverse selection and moral hazard would reduce the implementation of agricultural insurance ${ }^{[6,7]}$. Ma and Wang proposed the new method of using differential rate contracts menu to eliminate the adverse selection risk caused by asymmetric information through the analysis of the separating equilibrium conditions for the agricultural insurance market ${ }^{[8]}$. Their research suggested that the insurer should fully understand the agricultural products, agricultural insurance and other relevant information in order to establish the insurance contract menu. Based on the comparison on the two types of insurance products, which are between the farm production data and regional yield data of the cotton and soybean insurance in the Georgia and South Carolina, Deng and Barnett et al. found that multi-risk crop insurance based on the farm production was lack of efficiency. Therefore we could take regional yield data to avoid market failure caused by incomplete information ${ }^{[9]}$. In view of the present situation of agriculture in low income countries and relatively financial markets, Skees indicated that the agricultural insurance in low income countries should adopt the index insurance and make innovation to solve the adverse selection and moral hazard in the agricultural insurance market ${ }^{[10]}$.

In view of the adverse selection problem in agricultural insurance, the present research results have not considered the quality and safety risk, and the researches about adverse selection risk warning caused by the quality and safety of the information asymmetry for agricultural 
products are insufficient. However, agricultural products quality safety management is one of the effective ways to solve the problem of information asymmetry in agricultural insurance. This study starting from the safety of agricultural products, analyzed the adverse selection problem in agricultural insurance caused by quality and safety of the information asymmetry of agricultural products. Besides, it proposed the evaluation method of quality and safety risk based on ordered multinomial discrete choice model. The article is organized as follows: The second part describes the information asymmetry and adverse selection problems in agricultural insurance; The third part puts forward the adverse selection risk assessment and analysis method in agricultural insurance facing to the safety of agricultural products; The fourth part reports and analyzes the results of empirical research; The fifth part is the conclusion and Enlightenment.

\section{The Information Asymmetry and Adverse Selection Problems in Agricultural Insurance}

The term adverse selection was originally used in insurance. It describes a situation wherein an individual's demand for insurance is positively correlated with the individual's risk of loss, and the insurer is unable to allow for this correlation in the price of insurance. Agricultural insurance is the insurance refers to provide safeguard for the economic loss of agricultural producers who are engaged in farming and aquaculture production process caused by natural disasters and accident. So it is also known as the "two industry insurance". The insurance market is a typical information asymmetry market, whose main performance is the problem of adverse selection. It may also cause market failure of the agricultural insurance and result in low efficiency of insurance market operation.

\subsection{Agricultural Insurance and Adverse Selection}

The information asymmetry creates an imbalance of power in transactions which can sometimes cause the transactions to go awry, a kind of market failure in the worst case. The serious information asymmetry in the agricultural insurance practice leads to adverse selection and moral hazard. Akerlof created a precedent for adverse selection theory in the lemons model. Based on the existence of adverse selection ${ }^{[11]}$, Milgrom and Roberts designed the self-selection constraint characteristics of the insurance contract and studied on the problems of the insured risk classification and the competition equilibrium in the insurance market ${ }^{[12]}$. The research showed that adverse selection in the insurance market could be reduced through information transmission and information screening. The reasons resulting in adverse selection of the agricultural insurance mainly includes the following three aspects:

Firstly, the agricultural insurance has its particularity. This particularity is mainly reflected in that the farmers can't have sufficient information to make choice through on-site observation, and comparison when they're insuring, which is different from the general consumer. Meanwhile, the insurance commodity has no use value itself. The characteristics of the information that the policy-holders have contacted objectively determines that the problem of converse choice exists in the insurance market. Secondly, the insurance information acquisition cost is exorbitant. Under the information age environment, on the one hand, the channel of customers obtain insurance information is wider and the capacity is larger than before; on the other hand, the 
noise in the process of information obtain is also more. Therefore, the information asymmetry obviously exists between the ability to process information and limited rationality of customers and complicated information. However, refined effective information is more constrained by the customer's time, capacity etc. Thirdly, for the subject of insurance information disclosureagricultural insurance company, to accomplish effective information disclosure need to expend great cost. In addition to the need of spending a certain amount of manpower, material resources to classify the related business financial information and hunting for information release channels and other direct costs, but also a certain degree of hidden costs. It mainly includes the result of information disclosure which may lead to the disclosure of the company operations and commercial secret. And the information disclosure cost will lead the asymmetry of information between the insured and the insurance company.

Many scholars make the multiple dimensions study on the problems of adverse selection in the agricultural insurance. Some scholars started from farmers' behavior of purchase agricultural insurance, to determine whether the adverse selection phenomena exist in agricultural insurance or not. Estimating insurance demand equation of wheat farmers in Kansas, Goodwin found that the higher risk of farms lack flexibility on the insurance rate of change, which also showed that the existence of adverse selection in agricultural insurance. He also determined the existence of adverse selection phenomena through examining the relationship between demand elasticity and high risk insurance of the corn county level data in the Iowa State ${ }^{[13]}$. Just, Calvin and Quiggin analyzed national data to verify the problems of adverse selection in the United States crop insurance market ${ }^{[14]}$. The research showed that the farmers who had lower expected compensation have been screened out, and the participation in crop insurance scheme for farmers tend to have higher expected compensation. So in high risk county territory, the elasticity of demand in agricultural insurance is extremely small, which shows that the high risk farmers are willing to pay higher premiums for insurance. While, some scholars started from the insurance clause which is based on the insurance premium to explain the phenomenon of adverse selection in agricultural insurance. Because the determination of insurance rates is based on historical averages, and is limited to a certain geographical range, so insurance rates may not accurately reflect the real possibility of loss for individual farmers. The premium rate based on average leads to a typical problem of adverse selection. The research pointed out that adverse selection means that the insured have no ability to match the settings with the level of risk premium. So it is a direct result of reasonable premium rate. And there is plenty of evidence to suggest that the existence of adverse selection in insurance market.

\subsection{The Agricultural Insurance and Asymmetric Information}

Agricultural insurance has proven instrumental in transferring risks and stabilizing farm-

ers' income $^{[15]}$. The congenital vulnerability that our country ecological environment presents causes the agricultural production management to face a higher risk ${ }^{[16]}$. In the primary reasons causing adverse selection in agricultural insurance, the systemic risk and information asymmetry although take consideration of similarly the supplies side, compared with the systemic risk, the reasons cause information asymmetry are more incentives favored by researchers. Asymmetric information is mainly from the differences existing in information concerned with agricultural production practice and growing conditions that insurer and the insured have known, 
which could lead to the adverse selection and moral hazard problems common in the insurance market ${ }^{[17-19]}$.

On the one hand, the insured will take advantage of mastered information to seize interests, which the insurer is unable to observe. Although this benefit is based on the cost of insurer losses, thus the insurer faces moral hazard. The unique characteristics of agricultural insurance products make its risk higher than the other kinds of products.

On the other hand, differences in geographic location and management capacity of agricultural products, similarly can bring the different risks among farmers. So, when the insurer was not able to assess these risks scientifically, the problem of adverse selection occurred. Smith and Goodwin designed three kinds of empirical models for the wheat insurance behavior of peasant households in the state of Kansas: A single equation, simultaneous equations and bootsrapped. The results show that production inputs will be reduced when farmers have bought crop insurance ${ }^{[20]}$. Fang, according to survey data of 376 farmers from Hubei province, researchers analyzed the negative effect of the risk attitudes of farmers, the way of risk diversification and the ranking problem of agricultural insurance on agricultural insurance demand ${ }^{[21]}$.

\section{Agricultural Insurance Adverse Selection Risk Assessment of the Safety of Agricultural Products}

\subsection{Agricultural Risk and the Quality and Safety of Agricultural Products}

Agricultural insurance, serving as a safety net, increases farmers' ability to manage risks and enables them to devote more resources toward higher-quality agricultural inputs, including farming equipment and seeds ${ }^{[2]}$. Domestic and foreign scholars on agricultural risk classification and research to be divided according to the sources of risk. Some foreign scholars think agricultural risks mainly include two categories of natural risks and market risks. Which naturally risk is influenced by climatic conditions and other uncontrollable factors, making agricultural production yield and quality of agricultural products appears uncertain, and market risks including the risk of price fluctuation in the input and output of product. Also some scholars adopted many classification methods of agricultural risk, besides natural risk and market risk, agricultural risk also covers many aspects. Hardaker et al. conducted a typical agricultural risk and systematic classification, divided into agricultural production risk, market risk, currency risk, system risk, financing risk, legal risk and risk of life seven categories ${ }^{[23]}$. Boehlje considered along with the tremendous changes in the agricultural sector, agricultural industry growing convergence in the manufacturing, agriculture is also the emergence of new types of risk $^{[24]}$. Domestic scholars of risk classification also varies, Sun and Zhang think that agriculture in China in the transformation from planned economy to market economy, agricultural credit risk as a new type of agricultural risk. Under the background of ecological agriculture ${ }^{[25]}$, Zhang introduced the risk of environmental pollution into the division of agricultural risk ${ }^{[26]}$, and Liu introduced the resource risk into the division of agricultural risk ${ }^{[27]}$.

Nearly 30 or 40 years, agricultural prosperity due to fertilizers, pesticides, seeds, tractors and other production elements, and these elements on the contribution rate of production decreases. At the same time caused by the inappropriate agricultural production, operation of ecological disaster, and a large number of chemical substances and energy in serious harm to 
the environment and cause compaction, soil fertility decline, produce the phenomenon such as excessive pesticide residues, "natural agriculture", "ecological agriculture" and "regenerative agriculture" has become the development direction of agricultural production in the world today. Since the late 20th century, around the world appear constantly "mad cow disease", "disease" and "avian flu" disease, "food security" has received extensive attention all over the world. And as the source of the food chain of agricultural products, it is a focus in the field of today's global food security. In an increasingly competitive global economic environment, food quality safety risk as a new important content of agriculture risk areas. On the other hand with the development of economy, great changes have taken place in agricultural business spending patterns. The agricultural sources of a trend have appeared in the agricultural products supply chain integration. Safety of agricultural products based on quality chain management can lower the risk of agriculture, reduce the agricultural insurance in the risk of adverse selection caused by asymmetric information, and ensure the effective development of agricultural insurance.

\subsection{Agricultural Products Quality Safety and Good Agricultural Practices}

Risk assessment is the important technical basis of food safety management, which has become the important means to solve the problem of the quality and safety of agricultural products. Those developed countries in building based on the risk assessment of the risk management mode has made the positive exploration and actual operation ${ }^{[28]}$. Food safety risk analysis and early warning is macroeconomic early warning of a component, belonging to the single structured early warning. In view of the safety of agricultural products in special importance in the development of society, the world attaches great importance to agricultural product safety early warning work ${ }^{[29]}$. In 1975 the United Nations food and agriculture organization (FAO) has set up a "global agricultural products and agricultural information and early warning system (GIEVFS)", in stages, reporting shortage of global or regional agricultural production, providing fast and reliable future outlook information of agricultural products. FAQ was held in July 1991, the "strengthen early warning and Asia-pacific countries agriculture information system" work meeting.

The food safety quality control concept of "Farm to table" is already thorough popular feeling in recent years. The concept of good aquaculture practices and standards have been put forward. The good agricultural practices (good agriculture practice, GAP) provides help to achieve food security, food quality, production efficiency, livelihoods and the environment benefit specific medium and long-term goals, such as a means. Under the background of the development of ecological agriculture in 1991, the United Nations food and agriculture organization (FAO) held ministerial conference on agriculture and environment, made the famous declaration of "stearns, put forward" sustainable agriculture and rural development (SARD), the concept of widely support from the United Nations and countries. "Sustainable" has become the world's agricultural development of The Times. At the same time of ensuring the production of agricultural products, the better allocation of resources are required, which is to seek balance between agricultural production and environmental protection, and good agricultural practice is the key to sustainable agricultural development, but also an effective way to develop low carbon agriculture. In 1998 the United States department of agriculture (USDA) and the food and drug administration (FDA) for the first time in the form of official put forward good 
agricultural practices (GAP) requirements. In Australia the GAP guide is formulated by the competent department of agriculture, fisheries and forestry. Canadian food inspection agency issued in raw food plant origin bureau of ready-to-use vegetables specification operation, to reduce the safety hazard of ready-to-use vegetables, and to ensure the safety of vegetable food. GAP standard was first founded in 1997 by European retailers association (EUREP: Euro - retailer produce working group), it is through the third party inspection certification and the international unified standard to coordinate agricultural producers, processors, distributors and retailers of the production, storage and management. Global GAP, since its birth has maintained a strong momentum of development. GAP, according to the requirements of the "prevention is better than correction", provides a basic framework for the identification of the farm, food processing and transport and takes appropriate measures to minimize the risks. The farm location, breed, feed and agricultural water supply sources, field facilities, pesticide, chemical fertilizer, the rational use of drugs, breeding way, road transport, waste harmless handling, breeding of the records in the process of production, traceability, and training of employees, etc., have made a normative specification, build a basic framework of agricultural production and quality control ${ }^{[30]}$.

\subsection{The Agricultural Products Quality Safety Risk Assessment Based on the Dis- crete Choice Model}

Conditional logic model is one of the McFaddan's most important and most influential achievements on discrete choice behavior thought and behavior and he is one of the 2000 Nobel economics laureate. In multiple discrete choice model, Probit model selects a multivariate normal distribution function, then do nonparametric multivariate normal distribution test, so its application is restricted. The Logistic distribution is more suitable for the choice of distribution in the utility maximization, so the most used multiple discrete choice model is Logit model.

Ordered discrete choice model is one of the polynomial response model, it can solve the problem of "sequence" in the discriminant analysis. Ordered Logistic regression model is usually used "classnumber - 1", namely, a regression equation to describe the relationship between the independent variables (predictor variable) and the response variable:

$$
\operatorname{logit}[P(Y \leq k \mid X)]=\alpha_{k}+\beta_{1} x_{1}+\cdots+\beta_{m} x_{m}+\varepsilon_{m}, \quad k=1,2, \cdots,(\text { classnumber }-1)
$$

Among them, the function (1), $x_{1}, x_{2}, \cdots, x_{m}$ is the predictor variable, $\beta_{j 0}, \beta_{1}, \cdots, \beta_{m}$ is the parameters to be estimated. Through the sample observations it can estimate their value $\hat{\beta}_{j 0}, \hat{\beta}_{1}, \cdots, \hat{\beta}_{m}$, a value for predicting variables $x_{1}^{*}, x_{2}^{*}, \cdots, x_{m}^{*}$, it can get

$$
\begin{aligned}
& \ln \frac{q_{1}}{1-q_{1}}=\hat{\beta}_{10}+\hat{\beta}_{1}+\cdots+\hat{\beta}_{m}+\hat{\varepsilon}_{1} \\
& \ln \frac{q_{2}}{1-q_{2}}=\hat{\beta}_{20} \hat{\beta}_{1}+\cdots+\hat{\beta}_{m}+\hat{\varepsilon}_{2} \\
& \vdots \\
& \ln \frac{q_{k-1}}{1-q_{k-1}}=\hat{\beta}_{k-1,0} \hat{\beta}_{1}+\cdots+\hat{\beta}_{m}+\hat{\varepsilon}_{k-1}
\end{aligned}
$$

Through the equation (2), it can get the value of $q_{k-1}, \cdots, q_{3}, q_{2}, q_{1}$, and can get the probability 
$p_{1}, p_{2}, \cdots, p_{k}$ of $1,2, \cdots, k$ :

$$
p_{1}=q_{1}, \quad p_{2}=q_{2}-q_{1}, \quad \cdots, \quad p_{k-1}=q_{k-1}-q_{k-2}, \quad p_{k}=1-q_{k-1}
$$

Among them, the probability of $E_{j}$ is $p_{j}=P\left(E_{j}\right)$, if $p_{i}=P\left(E_{i}\right)$ is the maximum value, namely $F\left(E_{i}\right)=\max _{1 \leq j \leq k} P\left(E_{j}\right)$, then the predictive factors $x_{1}^{*}, x_{2}^{*}, \cdots, x_{m}^{*}$ belong to $E_{i}$.

Suppose a food safety risk assessment index set $C=\left\{c_{1}, c_{2}, \cdots, c_{m}\right\}, m \geq 2$ and $c_{i}$ represents the $i$ th discriminant index, then take the agricultural product security evaluation sample as follows: Evaluation experts carry out risk assessment for the $q$ base $v_{1}, v_{2}, \cdots, v_{q}, v_{j}$ representing the $j$ th base, and evaluate information is from the following languages evaluation set $S$, applying the 2-Tuple Linguistic to process Linguistic evaluation information ${ }^{[31]}$ :

$$
S=\left\{s_{0}=N, s_{1}=V L, s_{2}=L, s_{3}=M, s_{4}=H, s_{5}=V H, s_{6}=P\right\}
$$

Through gathering panel data to obtain the $i$ th a parameter values of the $j$ th base:

$$
x_{i}^{j}, \quad i=1,2, \cdots, m ; j=1,2, \cdots, q
$$

In accordance with the GAP standard, according to the characteristics of the vegetable gardens and the safety risk management requirements of agricultural products, it can set agricultural product security risk level to "relatively low(1), low (2), medium(3), relatively high (4), high(5)" five classes, marked as $E_{1}<E_{2}<\cdots<E_{5}$. Assume the probability of agricultural risk level " 1 , $2,3,4,5 "$ is $p_{1}, p_{2}, \cdots, p_{5}$, and point $q_{1}=P\left(E_{1}\right), q_{2}=P\left(E_{1} \cup E_{2}\right), \cdots, q_{4}=P\left(E_{1} \cup E_{2} \cup \cdots \cup E_{4}\right)$, $q_{5}=P\left(E_{1} \cup E_{2} \cup \cdots \cup E_{5}\right)$. If a base $v^{*}$ is prepared to be identified the risk, the index values of the risk assessment are $x_{1}^{*}, x_{2}^{*}, \cdots, x_{m}^{*}$. If $p_{i}=P\left(E_{i}\right)$ is the maximum, then the agricultural product security risk level is $E_{i}=\left\{E_{1}, E_{2}, \cdots, E_{k}\right\}$. The results of the agricultural products quality safety risk can be used as the basis for agricultural insurance adverse selection risk early warning, to reduce the adverse selection problem caused by the information asymmetry of agricultural product quality and safety.

\section{An Empirical Study - Based on the Survey of Vegetable Planting Base in Shandong Province}

\subsection{The Selection of Sample Base and the Profiles}

Shandong is one of the traditional agricultural products export province, and agricultural exports has become one of the major economic pillars. According to the Shandong province agriculture department bulletin, the speed of import and export of agricultural products in Shandong province both continuous speeding up in 2011, the total has broken through $\$ 15$ billion. At the same time import has topped $\$ 18$ billion, then on deficit for the first time in years. Agricultural products trade volume accounted for more than $60 \%$ of the total value added of the agriculture, three times the national average. Including five advantage products: Water seafood, vegetables, fruits, meat and peanuts and peanut products, their exports totaled $\$ 12.6$ billion, accounting for $82 \%$ of the total amount of agricultural exports in the province. According to Qingdao customs, Shandong port exports 3.896 million tons vegetables in 2011. Since the outbreak of the European debt crisis, the uncertainty and instability factors which are affecting agricultural exports have increased. The European debt crisis continues to spread, 
and part of sovereign debt risks are rising; The situation in the Middle East still turmoil; International commodity prices are high; Emerging economies facing inflationary pressures, so agricultural exports will face more and more challenges such as the increasingly fierce international competition and the increasingly stringent technical trade protection measures, etc. Thus though agricultural trade is maintaining stable growth in Shandong province, small and scattered agricultural growers, high breeding cage-free proportion, tend the hidden danger of exports of agricultural products in the producing, processing and marketing links etc have also emerged as obstacles to the agricultural product export trade development.

For the key factors such as chemical contaminants including pesticide residues, veterinary drug residues and non-edible additives limit Shandong food and agricultural products export in recent years, since 2007 in Anqiu city in Shandong province has proceeded pilot exploration of exported food safety regional management. Through the food safety management mechanism and innovation of the production and business operation mode, it has realized the joint of land into intensive and comprehensive management. Then since 2008, the government tallied up experience of Anqiu city, and it proceeded the agricultural products safety regionalization management demonstration area construction of exports food in more than 50 main counties (cities) which export food and agricultural products, establishing and improving the export of agricultural products quality safety standardization system, agricultural chemical downstream control system, the export of agricultural products quality safety traceability system, the export of agricultural products quality safety monitoring assessment and early warning system, furthermore Shandong popularized the GAP standards in the all planting and breeding base, in order to improve agricultural product international competitive power.

As important measures to service agriculture, rural areas and farmers, Shandong province has put forward to carry out policy-oriented agricultural insurance system pilot as early as 2006, covering the wheat, corn, cotton, greenhouse vegetables planting and breeding base, and it has obtained the good economic benefits. Combination of agricultural insurance in pilot and GAP planting base in the whole province, selected the Anqiu, Rushan Mountain, Rongcheng, Laixi, Juxian, Laiyang, Juye, Shenxian, Wendeng, Zhaoyuan, Shouguang, Jiaozhou, Feicheng, Linqu, Taian 15 vegetable planting base.

\subsection{The Construction of Adverse Selection Risk Assessment Index System for Agricultural Products Safety}

Shandong applied good agricultural practice (GAP) to the vegetable planting base management, providing the vegetable planting base management more scientific and standardization management methods. Through the requirements of the site selection, soil and irrigation water, seed, fertilizer, the use of plant protection products, harvesting, processing of agricultural products, identification, traceability system and records, etc. to strengthen the supervision during the crop planting and harvest post-processing, so it can ensure the source of security and risk identification. The vegetables planting base safety risk assessment index system of agricultural products according to the GAP standards is shown in Table 1, through the agricultural products safety risk assessment of the insurance base, it can cover the base of the risk information in time, thereby reducing agricultural insurance adverse selection risk which is caused by asymmetric information. 
Table 1 Vegetable planting base safety risk assessment index system of agricultural products

\begin{tabular}{|c|c|}
\hline assessment index & index description \\
\hline$C_{1}$ base selection & $\begin{array}{l}\text { the use conditions of base in the history, soil } \\
\text { analysis inspection situation, irrigation water } \\
\text { quality and environment condition surround- } \\
\text { ing the base. }\end{array}$ \\
\hline$C_{2}$ varieties and female parent selection & $\begin{array}{l}\text { the control of pesticide residues, heavy metal } \\
\text { control situation; the soil nutrient adequacy; } \\
\text { the suitability of soil structure conditions. }\end{array}$ \\
\hline$C_{3}$ the selection and use of manure & $\begin{array}{l}\text { water adequacy, suitability, quality, microbial } \\
\text { content suitability, irrigation water pollution } \\
\text { control situation. }\end{array}$ \\
\hline$C_{4}$ the management of environment problem & $\begin{array}{l}\text { base surrounding environment, ecological en- } \\
\text { vironment protection, resource conservation. }\end{array}$ \\
\hline$C_{5}$ the protection of crops & $\begin{array}{l}\text { the implementation of integrated pest man- } \\
\text { agement system, the selection and use of plant } \\
\text { protection products and management of pes- } \\
\text { ticide residues analysis. }\end{array}$ \\
\hline$C_{6}$ the management of irrigation & $\begin{array}{l}\text { irrigation water quality and risk assessment on } \\
\text { a regular basis, the preserve of irrigation water } \\
\text { record. }\end{array}$ \\
\hline$C_{7}$ the control of harvesting & $\begin{array}{l}\text { the risk assessment and control of harvesting, } \\
\text { health and standard training and implementa- } \\
\text { tion. }\end{array}$ \\
\hline$C_{8}$ the safety, healthy and welfare of staff & $\begin{array}{l}\text { employee's regular check-ups and infectious } \\
\text { disease control, staff training and protection } \\
\text { facilities equipment. }\end{array}$ \\
\hline$C_{9}$ the traceability system & $\begin{array}{l}\text { the effectiveness of the base traceability sys- } \\
\text { tem. }\end{array}$ \\
\hline $\begin{array}{l}C_{10} \text { the management of meeting emergency } \\
\text { and recall measures }\end{array}$ & $\begin{array}{l}\text { the formulation and implementation manage- } \\
\text { ment of emergency and the recall measures to } \\
\text { the risk such as natural disasters, etc. }\end{array}$ \\
\hline
\end{tabular}

\subsection{The Survey Information Summary of Sample Base Agricultural Products Safety Assessment}

In the popularization, application and practice of GAP, the evaluation result of agricultural products safety according to GAP standards is language information mostly, belonging to multiple indicators and group decision making, and has the characteristics of time sequence. Through the agricultural product safety information investigation in the GAP promotion and implementation of the selected 15 vegetable planting base, it can obtain the panel data of sample base evaluation information, as is shown in Table 2 (omit other base evaluation information). 
Table 2 Anqiu vegetable base information security risk assessment of agricultural products

\begin{tabular}{ccccccc}
\hline assessment index & 2008 & 2009 & 2010 & 2011 & 2012 & 2013 \\
\hline$C_{1}$ & $\mathrm{M}$ & $\mathrm{H}$ & $\mathrm{VH}$ & $\mathrm{VH}$ & $\mathrm{VH}$ & $\mathrm{H}$ \\
$C_{2}$ & $\mathrm{M}$ & $\mathrm{H}$ & $\mathrm{H}$ & $\mathrm{VH}$ & $\mathrm{H}$ & $\mathrm{M}$ \\
$C_{3}$ & $\mathrm{VH}$ & $\mathrm{VH}$ & $\mathrm{VH}$ & $\mathrm{P}$ & $\mathrm{VH}$ & $\mathrm{VH}$ \\
$C_{4}$ & $\mathrm{M}$ & $\mathrm{VL}$ & $\mathrm{H}$ & $\mathrm{H}$ & $\mathrm{VH}$ & $\mathrm{H}$ \\
$C_{5}$ & $\mathrm{H}$ & $\mathrm{H}$ & $\mathrm{VH}$ & $\mathrm{H}$ & $\mathrm{H}$ & $\mathrm{VH}$ \\
$C_{6}$ & $\mathrm{~L}$ & $\mathrm{M}$ & $\mathrm{VL}$ & $\mathrm{M}$ & $\mathrm{L}$ & $\mathrm{M}$ \\
$C_{7}$ & $\mathrm{H}$ & $\mathrm{H}$ & $\mathrm{VH}$ & $\mathrm{M}$ & $\mathrm{H}$ & $\mathrm{H}$ \\
$C_{8}$ & $\mathrm{H}$ & $\mathrm{H}$ & $\mathrm{M}$ & $\mathrm{H}$ & $\mathrm{M}$ & $\mathrm{M}$ \\
$C_{9}$ & $\mathrm{VH}$ & $\mathrm{H}$ & $\mathrm{M}$ & $\mathrm{H}$ & $\mathrm{VH}$ & $\mathrm{VH}$ \\
$C_{10}$ & $\mathrm{H}$ & $\mathrm{M}$ & $\mathrm{M}$ & $\mathrm{H}$ & $\mathrm{H}$ & $\mathrm{H}$ \\
\hline
\end{tabular}

Since the implementation of popularizing agricultural insurance, it has presented high loss ration in the field of planting and breeding business. The agricultural risks according to the survey show that the simple average overall loss ratio is as high as $85 \%$ above, and exceeding the critical point of $70 \%$ which is recognized. Agricultural products safety risk assessment can be implemented from the perspective of ecological risk to attain agricultural insurance risk early warning; as a result, higher agricultural products safety risk will lead to high loss ration of agricultural insurance. It could differentiate vegetables planting base level of risk via the ratio between the average overall loss ration of the investigation and the critical point ratio $70 \%$, as is shown in Table 3.

Table 3 The base risk level mapping

\begin{tabular}{cc}
\hline assessment index & $R=$ the average overall loss ration $/ 70 \%$ \\
\hline 1 & $R \leq 100 \%$ \\
2 & $100 \%<R \leq 120 \%$ \\
$3^{[32]}$ & $120 \%<R \leq 130 \%$ \\
4 & $130 \%<R \leq 150 \%$ \\
5 & $R>150 \%$ \\
\hline
\end{tabular}

The analysis and use of the assessment information depends on effective information gathering. Applied entropy method empowerment to gather panel data, and based on the characteristics of agricultural insurance risk assessment, and the recent risk data information is more valuable ${ }^{[32]}$, so according to the degree of time $\lambda=0.1$ to determine the weight vector is $W=(0.0029,0.0086,0.0255,0.0755,0.2238,0.6637)^{\mathrm{T}}$, then do time-weighted assemble to the evaluations information further, it can get vegetable base dynamic comprehensive evaluation results, as is shown in Table 4 . 
Table 4 The quality and safety risk assessment data summary of base

\begin{tabular}{ccccccccccccc}
\hline sample base & $C_{1}$ & $C_{2}$ & $C_{3}$ & $C_{4}$ & $C_{5}$ & $C_{6}$ & $C_{7}$ & $C_{8}$ & $C_{9}$ & $C_{10}$ & risk level \\
\hline 1 & 4.32 & 3.41 & 5.08 & 4.20 & 4.69 & 2.72 & 3.95 & 3.09 & 4.86 & 3.97 & 3 \\
2 & 5.19 & 2.28 & 4.32 & 5.00 & 5.06 & 4.22 & 4.71 & 3.46 & 5.02 & 4.18 & 1 & 5.12 \\
3 & 4.27 & 4.28 & 4.76 & 5.27 & 3.73 & 3.79 & 4.47 & 5.41 & 5.60 & 3.12 & \\
4 & 1.88 & 3.59 & 4.27 & 3.33 & 2.86 & 3.72 & 2.57 & 4.47 & 2.47 & 3.95 & 2 & 3 \\
5 & 3.57 & 3.88 & 4.07 & 3.52 & 4.89 & 3.50 & 4.65 & 4.23 & 4.66 & 3.14 & 3 \\
6 & 4.12 & 4.58 & 3.31 & 4.86 & 2.30 & 4.48 & 4.58 & 4.43 & 4.20 & 3.73 & 2 \\
7 & 3.76 & 5.23 & 3.58 & 1.90 & 3.20 & 5.13 & 3.92 & 3.77 & 4.20 & 4.36 & 3 \\
8 & 4.30 & 3.40 & 4.54 & 3.71 & 2.91 & 4.25 & 5.60 & 3.63 & 4.58 & 5.07 & 3 \\
9 & 3.40 & 4.29 & 4.52 & 3.96 & 3.07 & 4.51 & 5.39 & 4.59 & 4.05 & 3.29 & 2 \\
10 & 4.28 & 3.72 & 3.28 & 5.59 & 3.86 & 4.53 & 4.97 & 3.69 & 4.20 & 3.41 & 3 \\
11 & 4.67 & 4.31 & 3.94 & 2.91 & 5.50 & 4.59 & 5.68 & 3.03 & 4.36 & 3.72 & 3 \\
12 & 4.05 & 5.03 & 3.72 & 3.57 & 4.27 & 4.58 & 4.73 & 4.63 & 3.30 & 3.19 & 4 \\
13 & 4.68 & 4.29 & 4.52 & 2.97 & 3.88 & 3.53 & 3.38 & 4.74 & 3.95 & 3.57 & 5 \\
14 & 5.59 & 3.92 & 4.18 & 4.39 & 3.56 & 4.06 & 5.57 & 4.54 & 3.55 & 2.52 & 3 \\
15 & 3.07 & 3.36 & 4.27 & 4.71 & 2.67 & 3.69 & 5.20 & 4.20 & 3.74 & 2.29 & 3 \\
\hline
\end{tabular}

\subsection{Establish Quality and Safety Risks Discriminant Model}

According to the investigation data of agricultural quality safety from 15 sample base, it can build logistic regression model and do parameter estimation, then attain the regression equations:

$$
\begin{aligned}
\operatorname{logit}[P(Y \leq 1 \mid X)]= & 0.66744-0.9371 x_{1}-3.2708 x_{2}+0.0368 x_{3}+0.2633 x_{4}-0.5939 x_{5} \\
& +3.6057 x_{6}-0.5792 x_{7}-1.6645 x_{8}-0.2030 x_{9}-0.2756 x_{10} \\
\operatorname{logit}[P(Y \leq 2 \mid X)]= & 12.3472-0.9371 x_{1}-3.2708 x_{2}+0.0368 x_{3}+0.2633 x_{4}-0.5939 x_{5} \\
& +3.6057 x_{6}-0.5792 x_{7}-1.6645 x_{8}-0.2030 x_{9}-0.2756 x_{10} \\
\operatorname{logit}[P(Y \leq 3 \mid X)]= & 17.3055-0.9371 x_{1}-3.2708 x_{2}+0.0368 x_{3}+0.2633 x_{4}-0.5939 x_{5} \\
& +3.6057 x_{6}-0.5792 x_{7}-1.6645 x_{8}-0.2030 x_{9}-0.2756 x_{10} \\
\operatorname{logit}[P(Y \leq 4 \mid X)]= & 18.2973-0.9371 x_{1}-3.2708 x_{2}+0.0368 x_{3}+0.2633 x_{4}-0.5939 x_{5} \\
& +3.6057 x_{6}-0.5792 x_{7}-1.6645 x_{8}-0.2030 x_{9}-0.2756 x_{10}
\end{aligned}
$$

Table 5 and Table 6 show the Logistic regression analysis and goodness of fit test results. 
Table 5 The quality and safety risk assessment data summary of base

\begin{tabular}{ccccc}
\hline predictor & Coef. & SE Coef. & $\mathrm{Z}$ & $\mathrm{P}$ \\
\hline Const(1) & 9.66744 & 17.1987 & 0.56 & 0.574 \\
Const $(2)$ & 12.3472 & 17.1821 & 0.72 & 0.472 \\
Const $(3)$ & 17.3055 & 17.7058 & 0.98 & 0.328 \\
Const $(4)$ & 18.2983 & 17.7881 & 1.03 & 0.304 \\
$C_{1}$ & -0.937115 & 0.943289 & -0.99 & 0.320 \\
$C_{2}$ & -3.27082 & 1.74935 & -1.87 & 0.062 \\
$C_{3}$ & 0.0367558 & 2.28582 & 0.02 & 0.987 \\
$C_{4}$ & 0.263259 & 1.06566 & 0.25 & 0.805 \\
$C_{5}$ & -0.593933 & 1.02408 & -0.58 & 0.562 \\
$C_{6}$ & 3.60568 & 2.58070 & 1.40 & 0.162 \\
$C_{7}$ & -0.579169 & 1.17428 & -0.49 & 0.622 \\
$C_{8}$ & -1.66446 & 1.74582 & -0.95 & 0.340 \\
$C_{9}$ & -0.203027 & 1.18993 & -0.17 & 0.865 \\
$C_{10}$ & -0.275559 & 1.48865 & -0.19 & 0.853 \\
\hline
\end{tabular}

Table 6 Goodness of fit test results

\begin{tabular}{cccc}
\hline method & Chi-Square & DF & P \\
\hline Pearson & 29.7719 & 46 & 0.970 \\
Deviance & 25.2730 & 46 & 0.994 \\
\hline
\end{tabular}

\section{Results Analysis}

According to the quality and safety risks vegetable planting base discriminant model, direct to the following to be assessed bases information, as is shown in Table 7, it can carry out quality risk assessment.

To take the comprehensive evaluation value in Table 7 into Equation (6), then:

$$
\begin{aligned}
& \ln \frac{q_{1}}{1-q_{1}}=8.33327595, \quad \ln \frac{q_{2}}{1-q_{2}}=0.00000621 \\
& \ln \frac{q_{3}}{1-q_{3}}=0.00000004, \quad \ln \frac{q_{4}}{1-q_{4}}=0.00000002
\end{aligned}
$$

Solve the (7), then obtain $p_{1}, p_{2}, p_{3}, p_{4}, p_{5}$,

$$
\begin{aligned}
& p_{1}=q_{1}=0.10714352 \\
& p_{2}=q_{2}-q_{1}=0.89285028 \\
& p_{3}=q_{3}-q_{2}=0.00000616 \\
& p_{4}=q_{4}-q_{3}=0.00000003 \\
& p_{5}=1-q_{4}=0.00000002
\end{aligned}
$$


It turns out $\max p_{i}=P\left(E_{i}\right)=p_{4}$ by the the formula (8), so the quality and safety risk of the base could be identified as " 2 low", thereby it could not only to assess the base's agricultural insurance adverse selection risk, but also can be a basis for determining rates, thereby protecting the agricultural insurance business effectively.

Table 7 The quality and safety evaluation information of the base subjected to assess summary

\begin{tabular}{cccccccc}
\hline index & 2008 & 2009 & 2010 & 2011 & 2012 & 2013 & comprehensive evaluation value \\
\hline$C_{1}$ & $\mathrm{VH}$ & $\mathrm{M}$ & $\mathrm{L}$ & $\mathrm{M}$ & $\mathrm{L}$ & $\mathrm{L}$ & 2.0928 \\
$C_{2}$ & $\mathrm{VL}$ & $\mathrm{M}$ & $\mathrm{M}$ & $\mathrm{M}$ & $\mathrm{L}$ & $\mathrm{H}$ & 2.7704 \\
$C_{3}$ & $\mathrm{M}$ & $\mathrm{L}$ & $\mathrm{VL}$ & $\mathrm{M}$ & $\mathrm{VH}$ & $\mathrm{H}$ & 4.0517 \\
$C_{4}$ & $\mathrm{~L}$ & $\mathrm{H}$ & $\mathrm{M}$ & $\mathrm{H}$ & $\mathrm{M}$ & $\mathrm{M}$ & 3.0812 \\
$C_{5}$ & $\mathrm{H}$ & $\mathrm{L}$ & $\mathrm{M}$ & $\mathrm{M}$ & $\mathrm{M}$ & $\mathrm{M}$ & 2.9943 \\
$C_{6}$ & $\mathrm{H}$ & $\mathrm{H}$ & $\mathrm{VH}$ & $\mathrm{H}$ & $\mathrm{H}$ & $\mathrm{M}$ & 3.3618 \\
$C_{7}$ & $\mathrm{M}$ & $\mathrm{VH}$ & $\mathrm{P}$ & $\mathrm{H}$ & $\mathrm{H}$ & $\mathrm{M}$ & 3.393 \\
$C_{8}$ & $\mathrm{M}$ & $\mathrm{M}$ & $\mathrm{H}$ & $\mathrm{H}$ & $\mathrm{P}$ & $\mathrm{VH}$ & 5.0998 \\
$C_{9}$ & $\mathrm{H}$ & $\mathrm{VH}$ & $\mathrm{H}$ & $\mathrm{P}$ & $\mathrm{VH}$ & $\mathrm{H}$ & 4.3834 \\
$C_{10}$ & $\mathrm{VL}$ & $\mathrm{L}$ & $\mathrm{M}$ & $\mathrm{L}$ & $\mathrm{L}$ & $\mathrm{L}$ & 2.0226 \\
\hline
\end{tabular}

\section{Conclusion}

Agricultural insurance policyholders have mushroomed in recent years as China rolled out subsidy packages for the agricultural sector, which involves half of China's population. As policy tools to support the agricultural development, agricultural insurances is an important measure to solve the problem of "agriculture, rural areas and farmers". Establishing and perfecting the agricultural insurance system is of great significance to improve the system of agricultural risk management, improve agricultural ability to resist risks, promote the development of agricultural industrialization and marketization. To the question of adverse selection caused by asymmetric information in agricultural insurance practice, the author put forward that food quality and safety of agricultural products become the new agricultural insurance an important part in the global economic environment. Therefore, food safety risk assessment will effectively prevent the quality and safety adverse selection phenomenon caused by asymmetric information. According to the requirements of good agricultural practice (GAP) international standard, to the question of agricultural risk assessment analysis, propose an agricultural product quality safety risk assessment and early warning method based on the ordered classification discrete choice model. The above method by empirical research on vegetable planting base in Shandong, on the one hand, provides science and system engineering method to the agricultural planting base risk management; on the other hand, provides the reference to the vegetable planting base risk management in agricultural insurance practice.

The limitations of this paper are: Owing to the application time of agricultural insurance is shorter, the data collection and survey is certain constrainted, so less sample size. In addition, good agricultural practices as an international standard in the process of popularization and application, its evaluation information is mostly language information, belongs to the group 
decision-making, how to better gathering survey information is the problem to be further researched and improved in the future.

\section{References}

[1] Ahsan S M, Kurian N. Toward a theory of agricultural insurance. American Journal of Agricultural Economics, 1982, 64(3): 510-529.

[2] Quiggin J. The optimal design of crop insurance. Economics of Agricultural Crop Insurance. Norwell MA: Kluwer Academic Publishers, 1994.

[3] Coble K H, Knight T O, Pope R D, et al. Modeling farm — Level crop insurance demand with panel data. American Journal of Agricultural Economics, 1996, 78(2): 439-447.

[4] Miranda M J. Area yield crop insurance reconsidered. American Journal of Agricultural Economics, 1991, 73: 233-242.

[5] Wooldridge J M. Econometric analysis of cross section and panel data. Translated by Wang Z Y. Beijing: Renmin University Press of China, 1995.

[6] Chambers R G. Insurability and moral hazard in agricultural insurance markets. American Journal of Agricultural Economics, 1989, 71(3): 604-616.

[7] Hyde C E, Vercammen J A. Costly yield verification, moral hazard and crop insurance contrat form. American Journal of Agricultural Economics, 1997, 48(3): 393-407.

[8] Ma Z Y, Wang C Y. Economic analysis of information asymmetry and start crop insurance benefits. Journal of Yunan Finance \& Economics University, 2005(2): 58-60.

[9] Deng X H, Barnett J B, Vedenov D V, et al. Is there a viable market for area-based crop insurance. American Journal of Agricultural Economics, 2007, 89(2): 508-519.

[10] Skees J, Reed M. Rate making for farm level crop insurance: Implications for adversese lection. American Journal of Agricultural Economics, 1986, 68(3): 653-659.

[11] Akerlof G. Market for 'Lemons' quality uncertainty and the market mechanism. Quarterly Journal of Economics, 1970, 84: 488-500

[12] Milgrom P, Roberts J. Economics, organization and management. NJ: Prentice Hall, 1992

[13] Goodwin B K. Problems with market insurance in agriculture American. Journal of Agricultural Economics, 2001, 83(3): 643-649.

[14] Just R E, Calvin L, Quiggin J. Adverse selection in crop insurance: Actuarial and asymmetric information incentives. American Journal of Agricultural Economics, 1999, 81(4): 834-849.

[15] Hazell P B R. The appropriate role of agricultural insurance in developing countries. Journal of International Development, 1992(2): 57-581.

[16] Bhanti M, Taneja A. Contamination of vegetables of different seasons with organophosphorous pesticides and related health risk assessment in northern India. Chemosphere, 2007, 69: 63-68.

[17] Rothschild M, Stiglitz J. Equilibrium in competitive insurance markets: An essay on the economics of imperfect information. The Quarterly Journal of Economics, 1976, 90(4): 629-649.

[18] Miranda M, Vedenov D V. Innovations in agricultural and natural disaster insurance. American Journal of Agricultural Economics, 2001, 83(3): 650-655.

[19] Mosley P, Krishnamurthy R. Can crop insurance work? The case of India. Journal of Development Studies, 1995, 31(3): 428-450.

[20] Smith V, Goodwin B. Crop insurance, moral hazard, and agricultural chemical use. American Journal of Agricultural Economics, 1996, 78(2): 428-438.

[21] Fang L L. Research on China's agricultural insurance demand and subsidies. Huazhong Agricultural University, 2008.

[22] Serra T, Goodwin B. Featherstone: Modeling changes in the U.S. demand for crop insurance during the 1990s. Agricultural Finance Review, 2003(2): 109-125.

[23] Hardaker J B, Huirne R B M, Anderson J R. Coping with risk in agriculture. New York: CAB International, 1997.

[24] Boehlje M. Risk in U.S. agriculture: New challenges and new approaches. WestLatayette: Department of Agricultural Economics, Purdue University, 2002. 
[25] Sun L Y, Zhang Y H. Characteristics of agricultural risk and management in the transition period. Problem of Agricultural Economy, 2001(8): 20-26.

[26] Zhang Y. On the risks of agricultural production and agricultural industrialization. Zhejiang Academic Journal, 2001(2): 88-90.

[27] Liu W Z. Theory of high-tech in dissolve the functions of agricultural risk. Research of Agricultural Modernization, 2002(3): 226-228.

[28] Song Y. Food risk analysis theory and practice. Beijing: Standards Press of China, 2005.

[29] Xiao M, Yuan J P, Chen L Y. Influence factors and countermeasures for food safety. Transactions of the CSAE, 2007, 23(2): 286-289.

[30] Zhang D L, Gao Q S, Yang Z H, et al. Agricultural food quality safety evaluation and risk early-warning model. Systems Engineering — Theory \& Practice, 2010(6): 1125-1132.

[31] Herrra F, Martinez L A. Model based on linguistic 2-tuples for dealing with multigranular hierarchical linguistic contexts in multi-expert decision-making. IEEE Transactions on Systems, Man, and Cybernetics Part B, 2001, 31(2): 227-234.

[32] Guo Y J, Yao Y, Yi P T, et al. Method and application of dynamic comprehensive evaluation. Systems Engineering - Theory \& Practice, 2007(10): 155-159. 